\title{
Implementasi Algortima C4.5 Menentukan Pola Berangkatan Jamaah Haji
}

\author{
Fricles A Sianturi ${ }^{1}$, Mina Kumari ${ }^{2}$,Erlina Laian ${ }^{3}$ \\ 1,2 Jl. Iskandar Muda No.1, STMIK Pelita Nusantara Medan, Indonesia \\ E-mail : ${ }^{1}$ sianturifricles@gmail.com, ${ }^{2}$ minakumari@gmail.com, ${ }^{3}$ erlinalaian23@gmail.com
}

\begin{abstract}
Determination of the Hajj Pilgrim Departure Pattern is currently very much needed by the Haj organizers, especially at the Office of the Ministry of Religion Lubuk Pakam because the schedule of pilgrims' departure is still not regular, causing accumulation of data on pilgrims who will be departed to the holy land, but with The number of pilgrims who will depart for the pilgrimage is made to determine the pattern of Hajj departure with the C4.5 Algorithm to make it easier for the hajj organizer staff to determine what age should be sent to the holy land.
\end{abstract}

Keywords- C4.5 Algorithm, Determination of Hajj Pilgrims Departure Patterns

Abstrak-Penentuan Pola Keberangkatan Jama'ah Haji saat ini sangat dibutuhkan oleh pihak penyelenggara Haji Khususnya di Kantor Kementrian Agama Lubuk Pakam karena jadwal keberangkatan jama'ah haji masih belum teratur sehingga, menyebabkan penumpukan data jama'ah yang akan diberangkatkan ke tanah suci, akan tetapi dengan banyaknya jama'ah haji yang akan berangkat maka dibuatlah penentuan pola keberangkatan haji dengan Algoritma C4.5 untuk mempermudah para staff penyelenggara haji untuk menentukan usia berapakah yang seharusnya di berangkatkan ke tanah suci.

Kata kunci- Algoritma C4.5, Penentuan Pola Keberangkatan Jama'ah Haji

\section{PENDAHULUAN}

Para pendaftar ibadah haji di Kantor Kementrian Agama Lubuk pakam, calon jamaah haji diikut sertakan untuk mendaftar secara langsung diruang pendaftaran dengan memasukan (input) data informasi calon jamaah haji yang bersangkutan, baik berupa nama, jenis kelamin, umur, alamat, bank, dan data lainnya yang kemudian dimasukan dengan menggunakan Microsoft word dan Microsoft excel. Hal inilah yang menyebabkan antrian menjadi terlalu lama, karena cara menentukanjadwal keberangkatan haji dan mengisi data-data para calon jama'ah haji di Kantor Kemetrian Agama Lubuk Pakam bisa dibilang masi sangat manual. Oleh karena itu perlu adanya penentuan pola jadwal keberangkatan jama'ah haji dengan algoritma C4.5pada Kementrian Agama Lubuk Pakam.

Kementrian Agama pada bidang penyelenggara haji (PHU) sebagai fasilisator dan organisator masyarakat tentu harus bersikap profesional dalam melayani para calon jamaah haji untuk mendampingi dan membantu segala sesuatu yang dibutuhkan dan dipersiapkan oleh para calon jamaah haji sebelum keberangkatan sampai kepulangan ibadah haji[1],[2]. Dalam hal ini yang perlu ditangani dan mendapat perhatian khusus adalah bidang pelayanan haji yang mengingat 12 semakin banyak peningkatan masyarakat mendaftar ibadah haji semakin meningkat pula antrian untuk mendaftar dan antrian keberangkatan calon jama'ah haji di Kantor Kementrian Agama Lubuk Pakam[3],[4]

Metode C.45 yaitu sebuah algoritma yang digunakan untuk membangun decision tree (pohon keputusan) berdasarkan training data yang telah disediakan. Metode C4.5 dibuat oleh Ross Quinlan yang merupakan pengembangan dari ID3 yang juga dibuat oleh Quinlan (Quinlan, 1993) [5],[6]. Beberapa pengembangan yang dilakukan pada $\mathrm{C} 4.5$ adalah bisa mengatasi missing value, bisa mengatasi cintinue data, dan pruning [7].

Defenisi data mining adalah pembelajaran berbasis induksi (induction basedlearning) adalah proses pembentukan defenisi-defenisi konsep umum yang dilakukan dengan cara mengobservasi contoh-contoh spesifik dari konsep yang akan dipelajari. Knowledge Discovery in Database (KDD) adalah penerapan metode saintifikpada data mining [8],[9].

\section{METODE PENELITIAN}




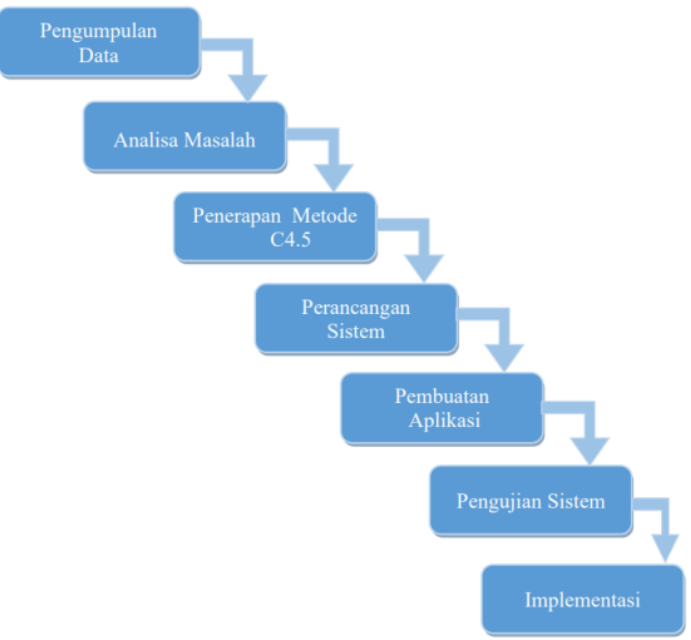

Gambar 1. Kerangka Kerja Penelitian

Berdasarkan kerangka kerja penelitian yang telah digambarkan di atas, maka dapat diuraikan pembahasan masing-masing tahap dalam penelitian adalah sebagai berikut [10],[11]:

1. Pengumpulan Data

Dalam memperoleh data-data, beberapa metode telah dilakukan guna mendapatkan data yang sesuai dengan kebutuhan peneletian.

2. Analisa Masalah

Analisa masalah yang diperoleh selama penelitian pada Kementrian Agama Lubuk Pakam dari hasil observasi serta wawancara sehingga masalah masalah dalam penelitian mendapat solusi. Penelitian membahas dan menyampaikan uraian hasil penelitian mengenai menentukan antrian jadwal keberangkatan calon jama'ah ibadah haji dengan menggunakan Algoritma C4.5.

3. Perancangan Sistem

Pada perancangan sistem tahapan yang menggambarkan rancangan bangun sistem yang dibuat dengan metode UML (Unified Modelling Language). Perancagan sistem ini terdiri dari perancangan Use Case Diagram, Activity Diagram, Sequence Diagram, Class Diagram dan Flowchart.

4. Pembuatan Aplikasi

Pada tahap pembuatan aplikasi melakukan perancangan sistem mengenai sistem aktivitas yang ada dibangun sistem dengan pemograman berbasis 41 WEB dengan bahasa pemograman HTML (HyperText Markup Language), CSS (Cascading Style Sheets), PHP (Hypertext Prepocessor), J-Query, dengan menggunakan aplikasi Sublime Text, dan menggunakan Database MySql, PhpMyAdmin.

5. Pengujian Sistem

Pada tahap pengujian data mining dalam menentukan antrian jadwal keberangkatan ibadah haji menggunakan C4.5. Proses pengujian membuktikan bahwa aplikasi telah sesuai dengan rancangan awal dari sistem yang telah dirancang dan telah memenuhi kebutuhan yang diharapkan.
6. Implementasi

Pada tahap Implementasi program diterapkan sesuai dengan tahap dimana sistem siap untuk digunakan di Kementrian Agama Lubuk Pakam untuk membantu menentukan antrian jadwal keberangkatan ibadah haji.

\section{HASIL DAN PEMBAHASAN}

Berdasarkan pengamatan, permasalahan ini dapat diatasi dengan cara melakukan pendataan kepada calon jama'ah haji di Kementrian Agama Lubuk Pakam dan penentuan pola keberangkatan dengan algoritma $\mathrm{C} 4.5 \mathrm{di}$ penyelenggara haji untuk mengatasi antrian jadwal keberangkatan jama'ah haji .

Sumber data pada penelitian ini di dapat dari Penyelenggara Haji di Kantor Kementrian Agama Lubuk Pakam. Contoh data yang digunakan yaitu data nama calon pendaftar haji dan data jadwal keberangkatan jama'ah haji, data tersebut digunakan sebagai sample analisa dan juga pengujian yang dapat dilihat pada table.

Tabel 1. Data Jemaah Haji

\begin{tabular}{|c|c|c|c|c|c|}
\hline $\begin{array}{c}\mathrm{N} \\
\mathrm{O}\end{array}$ & Nama & $\begin{array}{l}\text { Sisa Dana } \\
\text { Haji }\end{array}$ & $\begin{array}{c}\text { Pendidik } \\
\text { an }\end{array}$ & $\begin{array}{c}\text { Usi } \\
\text { a }\end{array}$ & $\begin{array}{c}\text { Berka } \\
\quad \mathrm{s}\end{array}$ \\
\hline 1 & sulaiman & $\begin{array}{c}\mathrm{Rp} .4,339,0 \\
00\end{array}$ & S1 & 24 & 50 \\
\hline 2 & Amnah & $\begin{array}{c}\mathrm{Rp} .4,339,0 \\
00\end{array}$ & S1 & 40 & 80 \\
\hline 3 & $\begin{array}{c}\text { Fatmawat } \\
\mathrm{y}\end{array}$ & $\begin{array}{c}\text { RP. } 2,956,0 \\
00\end{array}$ & S1 & 30 & 80 \\
\hline 4 & $\begin{array}{l}\text { Siti hajar } \\
\text { siregar }\end{array}$ & $\begin{array}{c}\text { RP. } 4,475,7 \\
00\end{array}$ & S1 & 35 & 70 \\
\hline 5 & $\begin{array}{c}\text { Sulaiman } \\
\text {, ST }\end{array}$ & $\begin{array}{c}\text { RP. } 4,475,7 \\
00\end{array}$ & S1 & 35 & 85 \\
\hline$\ldots$ & $\cdots$ & $\cdots$ & $\ldots$ & $\ldots$ & $\cdots$ \\
\hline$\cdots$ & $\cdots$ & $\cdots$ & $\cdots$ & $\cdots$ & $\cdots$ \\
\hline$\ldots$ & $\cdots$ & $\cdots$ & $\cdots$ & $\ldots$ & $\cdots$ \\
\hline 50 & $\begin{array}{l}\text { Nuraini } \\
\text { Siregar }\end{array}$ & $\begin{array}{l}\text { Rp.2,956,0 } \\
00\end{array}$ & S1 & 35 & 50 \\
\hline
\end{tabular}

Keterangan I(Persiapan Berkas):

a. Jika Persiapan Berkas $<60 \%$ maka keterangan "MINIMUM"

b. Jika Persiapan Berkas $>60 \%$ dan Persiapan Berkas $<84 \%$ maka keterangan "MEDIUM"

c. Jika Persiapan Berkas $>84 \%$ maka keterangan "MAXIMAL" 
a. Jika USIA<50 maka keterangan "Paruh Baya"

b. Jika USIA >31 dan USIA <50 maka keterangan "Tua"

c. Jika USIA >30 maka keterangan "TUA"

a. Jika Sisa Dana Haji <3.000.000 maka keterangan "RENDAH"

b. Jika Sisa Dana Haji >3.000.000 dan Sisa Dana Haji $<4.000 .0000$ maka keterangan "TUA"

c. Jika Sisa Dana Haji >4.000.000 maka Keterangan "TINGGI"

Untuk mengetahui kategori Keberangkatan Haji pada data Jemaah Haji , dapat dilihat dari Tabel 4.4 learning dataset II (kategorikal Keberangkatan Haji) berikut ini:

Tabel 2. Learning Data Set II (Kategorial Keberangkatan Haji)

\begin{tabular}{|c|c|c|c|c|c|c|}
\hline $\begin{array}{l}\mathrm{N} \\
\mathrm{O}\end{array}$ & Nama & $\begin{array}{c}\text { Sisa } \\
\text { Dana } \\
\text { Haji }\end{array}$ & $\begin{array}{l}\text { Pendid } \\
\text { ikan }\end{array}$ & $\begin{array}{l}\text { Us } \\
\text { ia }\end{array}$ & $\begin{array}{l}\text { Ber } \\
\text { kas }\end{array}$ & $\begin{array}{c}\text { Keberang } \\
\text { katan }\end{array}$ \\
\hline 1 & $\begin{array}{l}\text { sulaim } \\
\text { an }\end{array}$ & $\begin{array}{c}\text { Rp.4,33 } \\
9,000\end{array}$ & S1 & 24 & 50 & $\begin{array}{c}\text { Tidak } \\
\text { Prioritas }\end{array}$ \\
\hline 2 & $\underset{h}{\text { Amna }}$ & $\begin{array}{c}\text { Rp.4,33 } \\
9,000\end{array}$ & S1 & 40 & 80 & $\begin{array}{c}\text { Tidak } \\
\text { Prioritas }\end{array}$ \\
\hline 3 & $\begin{array}{c}\text { Fatma } \\
\text { waty }\end{array}$ & $\begin{array}{c}\text { RP. } 2,95 \\
6,000\end{array}$ & S1 & 30 & 80 & $\begin{array}{c}\text { Tidak } \\
\text { Prioritas }\end{array}$ \\
\hline 4 & $\begin{array}{c}\text { Siti } \\
\text { hajar } \\
\text { siregar }\end{array}$ & $\begin{array}{c}\text { RP.4,47 } \\
5,700\end{array}$ & $\mathrm{~S} 1$ & 35 & 70 & Prioritas \\
\hline 5 & $\begin{array}{l}\text { Sulaim } \\
\text { an, ST }\end{array}$ & $\begin{array}{c}\text { RP. } 4,47 \\
5,700\end{array}$ & S1 & 35 & 85 & Prioritas \\
\hline
\end{tabular}

\begin{tabular}{|c|c|c|c|c|c|c|}
\hline$\ldots$ & $\ldots$ & $\ldots$ & $\ldots$ & $\ldots$ & $\ldots$ & $\ldots$ \\
\hline$\ldots$ & $\cdots$ & $\cdots$ & $\ldots$ & $\cdots$ & $\ldots$ & $\cdots$ \\
\hline$\ldots$ & $\ldots$ & $\ldots$ & $\ldots$ & $\ldots$ & $\ldots$ & $\ldots$ \\
\hline 5 & Nurain & Rp.2,95 & S1 & 35 & 50 & Tidak \\
\hline 0 & $\begin{array}{c}\mathrm{i} \\
\text { Sirega }\end{array}$ & 6,000 & & & & Prioritas \\
\hline
\end{tabular}

Untuk menghitung entropy, ada beberapa proses yang harus didahului. Berikut adalah proses perhitungannya:

1. Proses Node Akar

Dimulai dari node akar, harus dihitung dulu entropy untuk node akar (semua data) terhadap komposisi kelas. Rumus menghitung entropynode akar adalah sebagai berikut:

$$
\operatorname{Entropy}(S)=\sum_{i=1}^{n}-p i \log _{2} p i
$$

Jadi Entropy $(\mathrm{S})=$
$\mathrm{E}($ seтиа $)=-(($ pi $(\mathrm{ya} \mid$ seтиа $) \quad \mathrm{x} \quad \log 2 \mathrm{pi}(\mathrm{ya} \mid$ seтиа $)) \quad+$ (pi(tidak|seтиa) x log2pi(tidak|semua))

$$
\left(-\left(\frac{32}{50}\right) x \log 2\left(\frac{32}{50}\right)\right)+\left(-\left(\frac{18}{50}\right) x \log 2\left(\frac{18}{50}\right)\right)=0.942683189
$$

\section{Hitung Entropy Atribut Persiapan Berkas}

Persiapan Berkas= Maximum

Entropy $($ Maximum $)=-(11 / 11) * \log 2(11 / 11)-(0 / 11)$

$* \log 2(0 / 11)=\mathbf{0}$

Persiapan berkas $=$ medium

Entropy (Medium) = $-(8 / 28) * \log 2(8 / 28)-$ $(20 / 28) * \log 2(20 / 28)$

\section{$=\mathbf{0 . 8 6 3 1 2 0 5 6 9}$}

Persiapan berkas $=$ minimum

Entropy $($ Minimum $)=-(1 / 11) * \log 2(1 / 11)-(10 / 11)$

* $\log 2(10 / 11)$

$=\mathbf{0 . 4 3 9 4 9 6 9 8 7}$

Setelah Entropydiperoleh lalu menghitung nilai Gain atribut Persiapan Berkas, dengan persamaan dibawah ini. Untuk menghitung gain setiap atribut rumusnya adalah:

$\operatorname{Gain}(A)=\operatorname{Entropy}(S)-\sum_{i=1}^{n} \frac{|S t|}{a} * \operatorname{Entropy}(S i)$ Gain $($ Persiapan Berkas $)=0.942-\left(\left(\frac{11}{50}\right) \times 0+\left(\frac{28}{50}\right) \times 0,863+\left(\frac{11}{50}\right) \times 0,439\right)$ Gain $($ Persiapan Berkas $)=0.362646334$

2. Hitung Entropy Atribut USIA

USIA = Paruh Baya

Entropy $($ Paruh Baya $)=-(14 / 16) * \log 2(14 / 16)-(2 / 16)$

$* \log 2(2 / 16)=0,543564443$

$\mathrm{USIA}=$ TUA

Entropy (TUA) $=-(16 / 19) * \log 2(16 / 19) \quad-(3 / 19)$

$* \log 2(3 / 19)=0,629249224$

USIA $=$ MUDA

Entropy $($ MUDA $)=-(2 / 15) * \log 2(2 / 15)-(13 / 15) *$

$\log 2(13 / 15)=0,566509507$

Setelah entropy diperoleh lalu menghitung nilai gain atribut USIA, dengan persamaan dibawah ini.

$\operatorname{Gain}($ USIA $)=0.942-\left(\left(\frac{16}{50}\right) \times 0,543+\left(\frac{19}{50}\right) \times 0,629+\left(\frac{15}{50}\right) \times 0,566\right)$ Gain $($ USIA $)=0.35967501$

Setelah mendapat entropy dan gain dari keseluruhan kasus, lakukan analisis pada setiap atribut dan nilainilainya lalu hasilnya ditampilkan seperti yang ada pada Tabel 3.

\begin{tabular}{|c|c|c|c|c|c|c|c|}
\hline Node & Atribut & Nilai & Jlh Data & Ya & Tidak & Entropy & Gain \\
\hline \multirow[t]{10}{*}{1} & \multirow{4}{*}{$\begin{array}{c}\text { Persiapa } \\
\text { n } \\
\text { Ber } \\
\text { kas }\end{array}$} & Maximum & 11 & 11 & 0 & 0 & \\
\hline & & Medium & 28 & 20 & 8 & 0.863 & \\
\hline & & Minimum & 11 & 1 & 10 & 1 & \\
\hline & & & & & & & 0,362 \\
\hline & \multirow[t]{4}{*}{ USIA } & Paruh Baya & 16 & 14 & 2 & 0,566 & \\
\hline & & TUA & 19 & 16 & 3 & 0,629 & \\
\hline & & MUDA & 15 & 2 & 13 & 0,566 & \\
\hline & & & & & & & 0,359 \\
\hline & \multirow{2}{*}{$\begin{array}{r}\text { Pendidi } \\
\text { kan }\end{array}$} & S1 & 47 & 31 & 16 & 0,925 & \\
\hline & & D3 & 2 & 1 & 1 & 1 & \\
\hline
\end{tabular}

Tabel 3. Analisis Atribut, Nilai Entropy dan Gain 


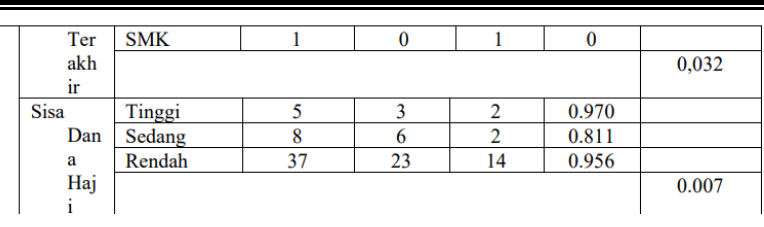

Pohon keputusan :

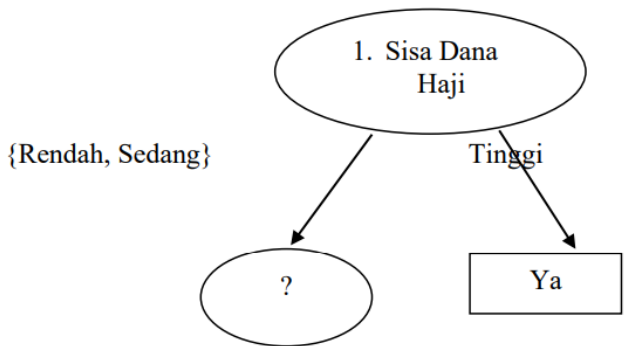

Gambar 2. Pohon Keputusan Node 1

Tabel 4. Data Persiapan Berkas Minimum

\begin{tabular}{ccccccc}
\hline No & Nama & $\begin{array}{c}\text { Sisa } \\
\text { Dan } \\
\text { a }\end{array}$ & $\begin{array}{c}\text { Pendid } \\
\text { ikan }\end{array}$ & $\begin{array}{c}\text { Usi } \\
\text { a }\end{array}$ & $\begin{array}{c}\text { Berka } \\
\text { s }\end{array}$ & $\begin{array}{c}\text { Keberang } \\
\text { katan }\end{array}$ \\
& & & & & \\
& & Haji & & & & \\
\hline 1 & Titik & Ting & S1 & & Mini & Tidak \\
& ngatmi & gi & & Mu & mum & \\
& n & & & da & & \\
& Tarsih & & & & & \\
& & & & & &
\end{tabular}

\begin{tabular}{ccccccc}
\hline 2 & $\begin{array}{c}\text { Sumar } \\
\text { no }\end{array}$ & $\begin{array}{c}\text { Seda } \\
\text { ng }\end{array}$ & S1 & $\begin{array}{c}\text { Mu } \\
\text { da }\end{array}$ & $\begin{array}{c}\text { Mini } \\
\text { mum }\end{array}$ & Tidak \\
\hline 3 & Amna & Seda & S1 & Tu & Mini & Ya
\end{tabular}

h ng a mum

\begin{tabular}{ccccccc}
\hline 4 & $\begin{array}{c}\text { Fatma } \\
\text { waty }\end{array}$ & $\begin{array}{c}\text { Ren } \\
\text { dah }\end{array}$ & S1 & $\begin{array}{c}\text { Par } \\
\text { uh } \\
\text { Ba } \\
\text { ya }\end{array}$ & $\begin{array}{c}\text { Mini } \\
\text { mum }\end{array}$ & Tidak \\
& & & & ya & \\
& & & & & \\
\hline 5 & Siti & Ren & S1 & $\begin{array}{c}\text { Par } \\
\text { hajar }\end{array}$ & Mini & Tidak \\
& dah & & uh & mum & \\
& siregar & & & Ba & & \\
& & & & ya & & \\
& & & & & &
\end{tabular}

\begin{tabular}{lllllll}
\hline$\ldots$ & $\ldots$ & $\ldots$ & $\ldots$ & $\ldots$ & $\ldots$ & $\ldots$ \\
\hline$\ldots$ & $\ldots$ & $\ldots$ & $\ldots$ & $\ldots$ & $\ldots$ & $\ldots$ \\
\hline$\ldots$ & $\ldots$ & $\ldots$ & $\ldots$ & $\ldots$ & $\ldots$ & $\ldots$
\end{tabular}

\begin{tabular}{|c|c|c|c|c|}
\hline $\begin{array}{c}\text { Siti } \\
\text { Fatima } \\
\text { h }\end{array}$ & $\begin{array}{l}\text { Ren } \\
\text { dah }\end{array}$ & S1 & $\begin{array}{c}\mathrm{Tu} \\
\mathrm{a}\end{array}$ & $\begin{array}{l}\text { Mini } \\
\text { mum }\end{array}$ \\
\hline
\end{tabular}

$\mathrm{h}$

Kemudian data di Tabel 4 dianalisis dan dihitung lagi entropy atribut Persiapan Berkas Minimum dan entropy setiap atribut serta gainnya sehingga hasilnya seperti data pada Tabel 4.8. Setelah itu tentukan pilih atribut yang memiliki gain tertinggi untuk dibuatkan node berikutnya. Adapun cara perhitungan entropy dan gain sama seperti langkah sebelumnya.

Jadi Entropy Kasus $(\mathrm{S})=$

$$
\left(-\left(\frac{1}{11}\right) x \log 2\left(\frac{1}{11}\right)\right)+\left(-\left(\frac{10}{11}\right) x \log 2\left(\frac{10}{11}\right)\right)=0.439496
$$

Dengan melakukan perhitungan pada setiap atribut didapatkan hasil sebgai berikut :

Tabel 5. Nilai Entrophy dan Gain

\begin{tabular}{|c|c|c|c|c|c|c|c|}
\hline NODE & & & $\begin{array}{r}\text { JUMLAH } \\
\text { KASU }\end{array}$ & TIDAK & YA & ENTROPY & GAIN \\
\hline \multirow[t]{13}{*}{1.1} & $\begin{array}{l}\text { PERSIAPAN } \\
\text { BERKAS } \\
\text { MINIMUM }\end{array}$ & & 11 & 10 & 1 & 0.439496987 & \\
\hline & \multirow[t]{4}{*}{$\begin{array}{c}\text { SISA DANA } \\
\text { HAJI }\end{array}$} & & & & & & 0.257678805 \\
\hline & & RENDAH & 8 & 8 & 0 & 0 & \\
\hline & & SEDANG & 2 & 1 & 1 & 1 & \\
\hline & & TINGGI & 1 & 1 & 0 & 0 & \\
\hline & \multirow[t]{4}{*}{ PENDIDIKAN } & & & & & & 0 \\
\hline & & SMK & 0 & 0 & 0 & 0 & \\
\hline & & D3 & 0 & 0 & 0 & 0 & \\
\hline & & $\mathrm{s} 1$ & 11 & 10 & 1 & 0.439496987 & \\
\hline & \multirow[t]{4}{*}{ USIA } & & & & & & \begin{tabular}{|l}
0.189052669 \\
\end{tabular} \\
\hline & & MUDA & 6 & 6 & 0 & 0 & \\
\hline & & TUA & 3 & 2 & 1 & 0.918295834 & \\
\hline & & $\begin{array}{l}\text { PARUH } \\
\text { BAYA }\end{array}$ & 2 & 2 & 0 & 0 & \\
\hline
\end{tabular}

Dari Tabel 5, gain tertinggi ada pada atribut USIA, dan Nilai yang dijadikan daun atau leaf adalah Banyak dan Sedikit karena nilai entropi 0.Jika divisualisasikan maka pohon keputusan tampak seperti Gambar 3:

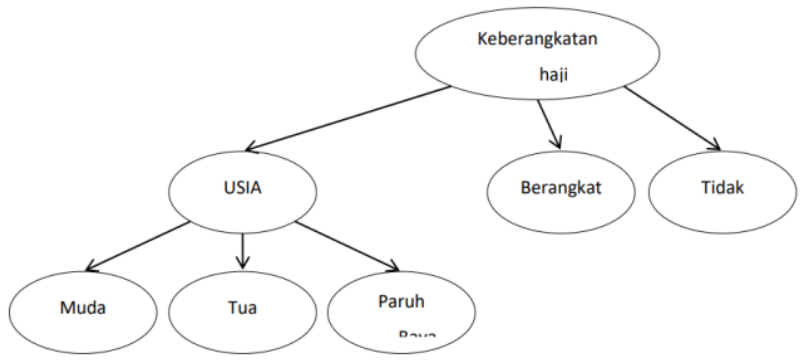

Gambar 3. Pohon Keputusan dengan Persiapan Berkas Minimum

\section{KESIMPULAN}

Kesimpulan dari Penentuan Pola Keberangkatan Jama'ah Haji dengan Algoritma C4.5 pada Kementrian Agama Lubuk Pakamyang telah diselesaikan ini dapat diambil beberapa kesimpulan diantaranya adalah. Permasalahan yang terjadi berkenaan dengan prioritas keberangkatan Jemaah Haji di Kemenag Lubuk Pakam dapat di selesaikan dengan menggunakan Algoritma C.45., Penentuan Pola Keberangkatan Haji Di Kementrian Agama Lubuk Pakamdengan menyesuaikan data penilaian agar dapat digunakan dengan Metode C-45. , Aplikasi yang mengadopsi Metode C-45telah dapat digunakan Untuk Menentukan Antrian Jadwal 
Keberangkatan Haji Di Kementrian Agama Lubuk Pakam.

\section{REFERENSI}

[1] F. A. Sianturi, "Analisa Decision Tree Dalam Pengolahan Data Siswa," MEANS (Media Informasi Analisa dan Sistem), vol. 3, no. 2, pp. 166-172, 2018, [Online]. Available: http://ejournal.ust.ac.id/index.php/Jurnal_Means/

[2] F. A. Sianturi, T. Informatika, and S. Utara, "Penerapan Algoritma Apriori Untuk Penentuan Tingkat," Mantik Penusa, vol. 2, no. 1, pp. 50-57, 2018, [Online]. Available: http://ejurnal.pelitanusantara.ac.id/index.php/mantik/article/vi ew/330

[3] M. Fahmi and F. A. Sianturi, "ANALISA ALGORITMA APRIORI PADA PEMESANAN KONSUMEN DI CAFÉ THE L . CO COFFE," SAINTEK (Jurnal Sains dan Teknologi), vol. 1, no. 1, pp. 52-57, 2019.

[4] E. Utari and P. M. Hasugian, "Menentukan Pola Hubungan Penyebab Kecelakaan Lalu Lintas Dengan Algoritma Apriori,” vol. 3, no. 3, pp. 127-132, 2021.

[5] K. R. Sitanggang and P. S. Hasugian, "Penerapan Data Mining Dalam Menganalisa Pola Peminjaman Buku di Perpustakaan SMP Negeri 2 Beringin Satu Atap Menggunakan Algoritma Apriori," JIKOMSI: Jurnal Ilmu Komputer dan Sistem Informasi, vol. 1, no. 1, pp. 1-5, 2018, [Online]. Available: http://ejournal.sisfokomtek.org/index.php/jikom/articl e/download/16/8

[6] E. Febrivani and R. Winanjaya, "Penerapan Data Mining Asosiasi Pada Persediaan Obat," vol. 3, no. 3, pp. 354-365, 2021.

[7] E. Febrivani and R. Winanjaya, "Penerapan Data Mining Asosiasi Pada Persediaan Obat," vol. 3, no. 3, pp. 354-365, 2021.

[8] S. Dengan, C. Algoritma, and W. Hidayati, "Data Mining Penentuan Tenaga Perawat Di RSUD Sultan," vol. 1, no. 2, pp. 1-7, 2018.

[9] A. S. Sitio, "Implementasi Keamanan Data Keuangan di SMK Swasta Musda Perbaungan Menggunakan Metode RC4," vol. 3, no. 3, pp. 60-66, 2021.

[10] R. Situmorang and F. A. Sianturi, "Implementation of Data Mining to Predict Stocks of Goods Using the Apriori Algorithm at Mom's Kitchen Bakery", J.Intell DSS, Intel DSS, jdss, vol. 3, no. 3, pp. 22-30, Sep. 2020

[11] M. Hartono and Fricles A Sianturi, "Penerapan Algoritma Apriori Dalam Menentukan Merek Pakaian Yang Paling Diminati Pada Darma Utama (DM Fashion)", JUMIN, vol. 3, no. 1 Desember, pp. 71-78, Dec. 2021. 